\title{
The Relationship between the Board Structure and Corporation Performance --- based on the Manufacturing Industry
}

\author{
Di YANG ${ }^{1, a}$, Juan-Juan WANG ${ }^{2, b}$ \\ ${ }^{1}$ Xi'an International Studies University, Business School, Xi'an, Shaanxi, China \\ ${ }^{2} X i ' a n$ International Studies University, Economics and Finance School, Xi'an, Shaanxi, China \\ ayd0818163@163.com, bwangjj64@163.com
}

Keywords: Manufacturing industry, Board of directors, Corporation performance.

\begin{abstract}
Corporate governance has become a worldwide topic in recent years. The main purpose of the corporation governance is to maximize the shareholders' profits. While, the board of directors is a vital part of corporate governance structure, playing an important role in decision-making and supervision. Whether the corporate could establish an efficient board of directors will affect corporate performance. Recently, the manufacturing industry develops at a highly speed and it contributes a lot in economic development, so the data from this industry is used to have a study on the relationship between board of directors and corporate performance. The paper reviews the former studies and based on related theories to analysis 200 listed companies in manufacturing industry by using SPSS. From the result, it shows that a suitable board size, more independent directors, more board meeting and so on could all improve the financial performance of the corporate.
\end{abstract}

\section{Introduction}

With the emerging of listed companies, the right of control and the right of operating are separated. Due to the separation, information between the shareholders and management becomes opaque and results in agency problem. Thus, the board of directors is a kind of institutional arrangement which is used to solve agency problems in modern companies. It plays an important role of decision-making and supervision in the corporate governance. Therefore, it has a big influence on the performance of corporate governance. A well-structured board does not only effectively restrict the manager's exclusive, but also reduce the cost of agency problem. To be the core position of corporate governance, the effectiveness and efficiencies of the board of directors is highly related to the stakeholders. There are several factors will affect the operation of the board of directors, and one of the most important factors is board structure. The structure of the board is a series regulations between the inside form and the proportion of the board. In order to supervise effectively and make decision scientifically, the followings would be considered to evaluate whether the structure of the board is proper: the scale of the board of directors, the percent of board's holding shares, the proportion of independence shareholders, the structure of the board leader, the number of the board meetings, the number of female directors and so on. And for corporate performance, it means that the achievement gains from the limited resource over a period, evaluating by the competitive of the company, the financial condition of the company, prospects for development and so on.

A large amount of experts have a study on the relationship between the scale of the board and the corporation governance, but it is not easy to get the best answer. Someone hold the idea that a larger amount of directors is good for the performance. Paul M Guest (2015) [7], the large scale of board would be more efficient. For a listed entity, in order to make the right decisions, the specialized knowledge is vital. So broaden the scale of the board can not only enrich the resource platform but also enhance the communication of the company, directors from different backgrounds could use their knowledge and experiences to make better decisions. However, Lipton and Lorsch (1992) [3] pointed out that small scale of the board would be more efficient. This is because as the scale of the board becoming larger, the board may speed more time to get a consistent conclusion and the 
efficiency of decision making could be lower. Nuno Fernandes (2008) [4], the scale of the board of directors and corporation performance is an inverted U - shaped curve. Based on He Yan's study, when the number of directors is less than 9, the scale and performance is positively correlated. But when the number of the directors is larger than 9, the board could be inefficiency and it has a negative relationship with the entity's performance.

While, others have done some research on the relationship between independent directors and corporate governance. Fama and Jensen(1983) [6], they hold the idea that independent directors is a role that can protect the shareholders' interest from damaging by the managers cause of the agency problem. And in the same time, the independent directors would give a various of fair and objective suggestions, maximizing the value of the shareholders. Black B. (2013) [1], the number of the independent directors is positive correlated with corporate performance. However, others think that when the number of independent directors is half of the board, the performance of the company is the best. Houda Arouri(2014) [2], a study on the listed companies implies that the number of the independent directors doesn't shows a positive effect on corporation performance. Also, the company with poor performance would set more independent directors in the following years, which makes investor annoyed.

Whether the chairman and manager is the same person also affects the corporate performance. On the one hand, Fama and Jensen(1983) [6], the chairman and the manager should be two different persons, only in this situation, the board can supervise the manager efficiently. Olayinka Marte Uadliale(2009) [5], the separation of the chairman and manger would strengthen the ability of the leadership of the board and the operation of the business. With the separation of chairman and manager, the agency cost could be reduced and improve the corporate performance. On the other hand, some people think the combination of chairman and manager can increase the performance. The reason for this conclusion is that they think the combination of the tow roles could reduce the communication cost and fasten the process of decision making. To some extent, it encourages the company to react more quickly and grasp more opportunities under a more reflex environment.

Furthermore, the number of board meetings could also exert an influence on corporate performance. Yermack, D.Higher (1996) [9], the more meeting the company hold, the better the corporation performance would be. With more board meetings, the directors of the company could communicate more information about the operation of the entity and have more discussions about the entity's business strategy and development. For Morck, Shleifer and Vishny (1988) [8], they use Tobin's Q as an indicator to analyze the share-holding of the board and find that, when the share-holding is under $5 \%$, the relationship between share-holding and performance is positive related. When the share-holding is between $5 \%$ and $25 \%$, the performance is of negative related. However, when the share-holding is upper than $25 \%$, it is also positive related. Based on the study of Yu Dongzhi(2013), which indicates that the share-holding of the directors doesn't have curve linear relationship with performance, but a linear relationship.

From the former studies, we find that different people hold different opinions on the relationship between board structure and corporate performance. In this paper, we use related data to analysis the relationship between board structure and performance in real estate industry.

\section{Related Theories}

\section{Agency Theory}

The agency theory is built on the asymmetric information. The main purpose of this theory is help to make appropriate decisions, improve supervision and motivation mechanism when the ownership and the control are separated in the entity. The theory emphases the interest conflict of the shareholders and the management because they are both rational economic man, the management may try to maximize their own benefit instead of the shareholders'.

\section{Stewardship Theory}

According to stewardship theory, it states that it is unreasonable to assume that opportunistic 
psychology and unscrupulous behavior choice of management in the theory of principal-agent theory. In reality, many managers choose to work hard instead of being lazy while consciously pursuing their personal pursuit. This theory doesn't agree with the idea that the board should contain a certain number of independent directors because it breaks one of the principles that the one who makes decisions for the entity should be the person who knows the operation of the entity most. So this kind of board is invalid. And form this theory, we could also get the thought that the chairman and the manager should be the same one, which would be beneficial to the innovation of the management, helping the company to be more flexible, reducing the cost of communication and improving corporation performance.

\section{Resource Dependence Theory}

Resource dependence theory confirms that the board of directors, as a decision-making part, should have the inside structure which meets the need of outside market. Such as, the new directors entering in the listed company aim to enhance the ability of gathering capital. The reputation of the new directors can also strengthen the company's reputation. So the company can deal with the threats through changing the board structure, in order to adapting to the flexible environment. The professional knowledge of the director help the company make decisions more quickly and more efficient.

\section{Insider Control Theory}

Lacking of the management knowledge and the existing of asymmetric information, the agent may ignore the interest of the company. What's more, the management will manipulate the profit and maximize his own interest, such as, distorting the financial data, or skimming off the property of the company. So the company should enhance the independent regulation of the directors, in the same time, improving the innovation mechanism.

\section{The Relationship between the Structure of Board and Corporation Performance}

Based on the former study and the related theories, we could get some conclusions about the mechanism between board structure and corporate performance.

\section{The Scale of the Board of Director and the Corporation Performance}

Firstly, according to the principal-agency theory, a small scale of directors is more likely to improve the performance. According to the principal agent theory, small scale of the board can reduce the cost of communication and coordination, which improves the efficiency of the process of decision making. Especially in a fast changing market, the low efficiency of decision-making would hinder the development of the company, reducing the performance and increasing the agency cost.

Secondly, a large scale of directors is more likely to improve the performance. Basing on the resource dependence theory, more directors can bring more outside resource to the company, such as the director from the bank can help the company to get the fund easily. By the same time, more directors can also bring a various of advices for the decision-making, avoiding the possibility of mistakes.

Thirdly, a proper scale of directors is more likely to improve the performance. Large or small board would both have the advantages and disadvantages. So, a proper scale of director would be more suitable for the corporation. Being higher or lower would impact the performance of the company. Thus, inverted $\mathrm{U}$ - shaped curve would be more reasonable.

\section{The Proportion of the Independent Directors and Corporation Performance}

According to the Principal agent theory, the larger proportion the independent directors would be, the less cost of the agency and inside control would be.

According to the Resource Dependence Theory, most of the independent directors are professors, the bankers and other outstanding person, providing the company with superior outside resource, specialized knowledge and positive image. Therefore, maybe a large proportion of the independent 
directors would increase the corporation performance.

Secondly, the independent directors don't work in the company, so they may not have an overall outstanding, losing the best time for the company to invest. Also, a majority amount of the independent directors are part-time, so the may not have the enough time to be an efficient supervisor. In the same time, a director may work in not only one company, so the time and energy they spend on the company should be doubted. So a small proportion of the independent directors would increase the corporation performance.

\section{Whether the Chairman and the Manger are one Person}

The Principal Agent Theory, Resource Dependence Theory and Insider Control Theory all state that the separation of the chairman and manager would help the board of directors to be more independent and efficient. The board of directors can effectively perform the supervisory functions, reduce the agency costs between shareholders and managers, and enhance company's performance. Thus, the separation of the two positions would lead to a increase in the performance.

According to the Stewardship Theory, the combination of two positions could reduce the communication and coordination cost between the chairman and manager, improve the enterprise's freedom of innovation, and help the enterprise seize the opportunity in a rapidly changing market environment. Which in turn help to improve the business performance. Thus, the chairman and the manager should be one person, which can improve the performance.

\section{The Number of the Board Meetings}

The number of the board meetings means that how many meetings would a board held every year. About this topic, there are two different views on it. One is that, they think that the number of the meeting is liner positive with the corporation performance, and also advice that the meeting should be held once a month, lasting for one day. While, some people think that the board meeting is a form, without the actual meaning.

\section{Empirical Analysis}

In recent years, a lot of experts have studied on the board structure and the corporation performance. They hold the different views on this hot topic. So, this paper would base on the statistic of listed companies, using the empirical analysis to confirm whether there would be a relationship between the two elements.

\section{Theoretical Hypothesis}

\section{The Scale of the Board of Directors and the Corporation Performance}

The Agency Theory states that a small scale of directors is more likely to improve the corporation governance efficiency. But the Resource Dependence Theory states that more directors are likely to improve the corporation governance. In the listed company of China, the major shareholders and the insiders control the company. So increasing the number of board of directors would reduce the agency cost and increase the value of the company.

Hypothesis 1: The scale of the board of director and the corporation performance has a positive correlation.

\section{The Condition of the Chairman and the Manger}

Whether the chairman and the manger is authorized to be one person has a big influence on the function of the board of directors. The integration of the two positions means that the control power of the board would be reduced.

Hypothesis 2: The separation of the chairman and manager has a positive correlation with the corporation performance.

\section{The Proportion of the Independent Directors and Corporation Performance}

The theory confirms that the independent director is a necessary part of the board of directors. The 
independent director can supervise the management, which can promote the management and shareholders have the same interest, being efficient for the development and performance.

The manger holding a large amount of information, so it is easy for them to be the manager of the organization, betraying the aim of shareholders. Once the board of directors is controlled by the managers, there is a risk that the managers may collude with others and do something which will destroy the interests of the shareholders. So, the independent directors can prevent the board from the wrongful management.

Hypothesis 3: The proportion of the independent directors is positive related with the corporation performance.

\section{The Number of the Board Meetings}

About the board meetings, the board of the directors can get together to talk about the management affairs and development of the company. The communication could make the decision-making more helpful and reasonable.

Hypothesis 4: The number of the board meetings is positive correlated with the corporation performance.

\section{Research Methodology and Results}

\section{Sample and Data Sources}

The source of the sample and data is effective and authentic. Firstly, this paper bases on the samples of the manufacturing companies' A shares from 2014-2016, which is listed on the Shanghai Stock Exchange and Shenzhen Stock Exchange, excluding the ST and PT companies. Secondly, sample homogeneity is also a vital part. The paper, basing on the manufacturing companies of A shares, is comparable and persuasive. Research ideas of this paper are to screen the representative variables of measurement of the board of directors and corporation performance. The structure of the board is the independent variables and the performance of the corporation is the dependent variable. Using the description and the liner analyze to define the relationship between the two elements. SPSS and excel would be the aided analysis.

\section{The Definition of the Variables}

There are three kinds of variables in this paper, explained variables, explanation variables and control variables. Explained variables reflect the financial index of corporation performance. The performance index can be measured by the profit index and non-profit index. So in this paper the profit index is chose to evaluate the corporation performance. For instance, the net profit, net income, earnings per share, return on net asset and so on. This paper chooses the EPS as the performance variable.

Table 1 The symbol of variables

\begin{tabular}{|l|c|}
\hline Variables & Symbol \\
\hline Performance Variables & EPS \\
\hline Explanation Variables & BS \\
\hline Board Scale & IN \\
\hline The proportion of independent directors & CM \\
\hline The condition of chairman and manager & NM \\
\hline The number of the board meeting & \\
\hline Control Variables & CAPITAL \\
\hline Scale of the company & DEBT \\
\hline Capital Structure & \\
\hline
\end{tabular}

The different factors which affect the structure of board are indicated by the explanation variables. The explanation variables reflect the elements affecting the structure of the board of directors. The paper chooses four variables of the structure of the board: the scale of the board of directors, the 
number of the independent directors, the duality of the manager and chairman and the number of the board meetings. In the paper, the scale of the board of directors is defined as the number of the directors in the board of directors of the company. And the proportion of the independents directors is the occupation rate of independent directors of the total directors in a company's board. The duality of the chairman and manager is defined as the virtual variables, which use 0 and 1 to represent the combination or not. When the chairman and manager is one person, 1 should be taken, otherwise 0 . And the control variables are used to control certain influence factors to get the real results. There are a lot of control variables of the company. This article would use two of them to evaluate the company.

\section{The Design of the Model}

The aim of the model is to define whether the hypothesis is tenable.

$$
\text { EPS }=\mathrm{a} 0+\mathrm{a} 1 \mathrm{BS}+\mathrm{a} 2 \mathrm{IN}+\mathrm{a} 3 \mathrm{CM}+\mathrm{a} 4 \mathrm{NM}+\mathrm{a} 5 \mathrm{Capital}+\mathrm{a} 6 \mathrm{Debt}+\varepsilon
$$

a0: the intercept, a1, a2, a3, a4, a5,a6 are the regression coefficient, $\varepsilon$ is the random error.

Table 2 The Scale of the Board

\begin{tabular}{|c|c|c|c|c|c|c|}
\hline \multirow{2}{*}{$\begin{array}{c}\text { The scale of the } \\
\text { board of directors }\end{array}$} & \multicolumn{2}{|c|}{2014} & \multicolumn{2}{c|}{2015} & \multicolumn{2}{c|}{2016} \\
\cline { 2 - 7 } & Company & Ratio & Company & Ratio & Company & Ratio \\
\hline $3-5$ & 26 & $13.15 \%$ & 24 & $12.0 \%$ & 24 & $12.0 \%$ \\
\hline $6-8$ & 44 & $22.18 \%$ & 40 & $20.0 \%$ & 40 & $20.0 \%$ \\
\hline $9-10$ & 102 & $50.6 \%$ & 110 & $55.0 \%$ & 112 & $56.0 \%$ \\
\hline $11-15$ & 24 & $12.10 \%$ & 24 & $12.0 \%$ & 22 & $11.0 \%$ \\
\hline Above 15 & 4 & $1.99 \%$ & 2 & $1.0 \%$ & 2 & $1.0 \%$ \\
\hline Total & 200 & $100 \%$ & 200 & $100 \%$ & 200 & $100 \%$ \\
\hline
\end{tabular}

Table 3 Descriptive analysis of the scale of board

\begin{tabular}{|c|c|c|c|}
\hline Year & 2014 & 2015 & 2016 \\
\hline Mean Value & 9.9556 & 9.9952 & 9.9962 \\
\hline Mid- Value & 9 & 9 & 9 \\
\hline Standard Deviation & 4.8233 & 4.7232 & 4.8652 \\
\hline Maximum & 15 & 16 & 15 \\
\hline Minimum & 3 & 3 & 2 \\
\hline Samples & 200 & 200 & 200 \\
\hline
\end{tabular}

It is easily to see that most companies have a scale 9 to 10 persons in a board. From 2014 to 2016, more companies choose to keep the scale of the company at 9 to 10 people, which even up to $56.0 \%$ of the total. More directors may bring a large amount cost of the communication. The maximum and minimum amount has a big difference, because different company may decide the board size according to their own situation.

Table 4 Proportion of the independent directors

\begin{tabular}{|c|c|c|c|}
\hline & 2014 & 2015 & 2016 \\
\hline & Ratio & Ratio & Ratio \\
\hline Under $20 \%$ & $3.26 \%$ & $3.19 \%$ & $3.24 \%$ \\
\hline $20 \%-35 \%$ & $67.04 \%$ & $68.32 \%$ & $68.66 \%$ \\
\hline $35 \%-50 \%$ & $28.20 \%$ & $27.00 \%$ & $26.59 \%$ \\
\hline Above $50 \%$ & $1.50 \%$ & $1.49 \%$ & $1.51 \%$ \\
\hline Total & $100 \%$ & $100 \%$ & $100 \%$ \\
\hline
\end{tabular}


Table 5 Descriptive analysis of the proportion of independent directors

\begin{tabular}{|c|c|c|c|}
\hline & 2014 & 2015 & 2016 \\
\hline Mean Value & 0.3325 & 0.3229 & 03349 \\
\hline Variance & 0.3432 & 0.3229 & 0.3356 \\
\hline Standard Deviation & 0.0041 & 0.0037 & 0.0028 \\
\hline Maximum & 0.5829 & 0.6000 & 0.6000 \\
\hline Minimum & 0 & 0 & 0 \\
\hline
\end{tabular}

From the tables above, the proper proportion of the independent directors is between $20 \%$ to $35 \%$. From 2014 to 2016, this amount is increasing slowly. There are not too many independent directors which above $50 \%$ in the companies. The mean value is about $3.2 \%$ and the standard deviation is not too big. The minimum amount is zero, which means in the sample used in this paper, all companies have independent directors in the board.

Table 6 The duality of the two positions

\begin{tabular}{|c|c|c|c|c|c|c|}
\hline & 2014 & & 2015 & & 2016 & \\
\hline & Company & Ratio & Company & Ratio & Company & Ratio \\
\hline Integration & 18 & $9.00 \%$ & 21 & $10.50 \%$ & 23 & $11.50 \%$ \\
\hline Separation & 182 & $91.00 \%$ & 179 & $89.50 \%$ & 177 & $88.50 \%$ \\
\hline Total & 200 & $100 \%$ & 200 & $100 \%$ & 200 & $100 \%$ \\
\hline
\end{tabular}

Most companies' chairman and the manager are not the same person. So, the chairman could not be influenced by the management and maybe could give reasonable advices on the operation of company. While, on the other hand, it may result a slowly decision making process and increase the agency cost.

Table 7 The number of the board meetings

\begin{tabular}{|c|c|c|c|}
\hline & 2014 & 2015 & 2016 \\
\cline { 2 - 4 } & Company & Company & Company \\
\hline $4-6$ & 62 & 105 & 85 \\
\hline $7-9$ & 107 & 80 & 85 \\
\hline $10-14$ & 26 & 11 & 26 \\
\hline $15-$ & 4 & 4 & 4 \\
\hline Total & 200 & 200 & 200 \\
\hline
\end{tabular}

From the table we can conclude that for most companies, they hold 7 to 9 meetings a year. In total, from 2014 to 2016, the number of meetings has decreased to some extent. Maybe for the companies, they think it is suitable to for them to have 7 to 9 times of meeting and this amount could help them have a better communication with each other about the development of the companies.

Table 8 EPS

\begin{tabular}{|c|c|c|c|}
\hline EPS & 2014 & 2015 & 2016 \\
\hline Minimum & -.76 & -.80 & .78 \\
\hline Maximum & 4.01 & 4.20 & 4.03 \\
\hline Mean Value & 0.5690 & 0.5216 & 0.4920 \\
\hline Standard Value & 0.9432 & 0.9324 & 0.9233 \\
\hline Variance & 0.925 & 0.892 & 0.921 \\
\hline
\end{tabular}

Based on the table, it is obviously that the mean value of earnings per share is decreasing from 
2014 to 2016. It means the companies may pay more attention on performance and try to improve the performance by adjusting the structure of company.

Table 9 Correlation and regression analysis

\begin{tabular}{|c|c|c|c|c|c|}
\hline & & BS & IN & CM & NM \\
\hline BS & Pearson relevance & 1 & $-0.41^{* *}$ & $-0.134^{*}$ & $0.182^{* *}$ \\
\hline & Significance(bilateral) & & 0.000 & 0.012 & 0.000 \\
\hline IN & Pearson relevance & -0.390 & 1 & 0.100 & 0.015 \\
\hline & Significance(bilateral) & 0.000 & 0.037 & 0.879 & 0.765 \\
\hline CM & Pearson relevance & $-0.133^{*}$ & $-0.109^{*}$ & 1 & -0.085 \\
\hline & Significance(bilateral) & 0.012 & 0.037 & & 0.105 \\
\hline NM & Pearson relevance & $0.186^{* *}$ & 0.015 & -0.085 & 1 \\
\hline & Significance(bilateral) & 0.000 & 0.755 & 0.105 & \\
\hline
\end{tabular}

**. significant correlation on 0.01 level(bilateral)

*. significant correlation on 0.05 level(bilateral)

\section{Conclusion and Suggestions}

\section{Conclusion}

The board of the directors is the main character in the corporation governance, enhancing the management of the company and preventing the manager from making profit for themselves. And at the same time, the scale of the board, the number of independent directors, the number of board meeting and the duality of chairman and manager are the factors which affect the structure of the board of directors. The inside directors are in charge of the daily operation, having the massive information of the company and having the deep understanding of the corporation management, helping the board of directors make the reasonable decision. However, the outside directors are not the main investors of the company. Their aims are to maintain the interest of the shareholders, also being specialists in a kind of industry. They could give the reasonable, objective and independent advice if the incentive mechanism and restrict mechanism is proper.

According to the previous analysis, in the manufacturing industry, the scale of the board of the directors has the negative correlation with the cooperation performance, so the hypothesis 1 is not valid. However, the proportion of the independents shareholders is positive correlation with the performance. So the hypothesis 2 is true. And, according to the tables below, whether the chairman and the manager is one person seems not making any difference. So the hypothesis 3 is not valid. The last one, the number of the board meetings is showing a positive correlation with the corporation performance.

\section{Suggestions}

As the operator of the company, the board of directors plays an important role in the company. Thus, the structure of the board of directors is influential in the company.

Firstly, the proper scale of the board is a best choice for the whole company. Small scale of the board of directors might be hard for them to supervise effectively, however large scale of the board might reduce the speed of the decision-making and increase the cost. Meanwhile, the company needs to enhance the position of the board of directors and the function of the board of directors. From the perspective of economy, the most popular view of the corporation governance might be the Agency Theory. It defines that the board of the directors is an instrument which supervise the managers' behavior.

Secondly, the independent directors are a necessity of the company. The independent directors help the board to be more efficient. So the company needs to improve the independent board system. In some companies, the independent directors are not as important as the executive directors, which result the corporation lack supervision and independence. (1) The manufacturing industry need to clearly define what is the actual obligation of the independent directors. They should have enough 
time to operate the board of directors with the specialized skills. (2) Improve the system to choose suitable independent directors, avoiding the manipulation of insider directors. (3) Increasing the number of the independent directors to make sure that the independent directors occupies a large part of the board of directors. (4) To establish an effective independent director restraint mechanism.

Thirdly, although many persons consider that the chairman and the manger should be separated, the analysis above shows that it should depend on the condition of the company. In the manufacturing industry of China, the chairman and the manager just keep few or a small proportion of the shares. So, the law or the incentive mechanism is not enough for them. So in this condition, the chairman is difficult to supervise the manger efficiently. Thus, the manipulation between the two positions is also hard to be defined. If the two position is separated, the innovation of the manager would restricted by the chairman. And at the same time, the communication cost would also increase a lot. So whether the two positions need be separated should link to the environment of the company.

Fourthly, the board meeting is also a positive correlation with the corporation performance. So the company needs to have more board meetings to let the board of directors communicate with each other and avoid lack of communication and interest conflict. Also, when the company was going to have the board meeting, they could also invite the shareholders to their meetings. In this way, the mangers could communicate and discuss the business with the shareholders to decrease the cost of agency problem.

\section{Acknowledgement}

This research was financially supported by the project of research on the construction of the operation guarantee system of cold chain logistics of agricultural products of Shaanxi province.

\section{References}

[1] Black B, Kim W. "The Effect of Board Structure on Firm Value: A Multiple Identification Strategies Approach Using Korean Data.”Journal of Financial Economies June.2012:104-106.

[2] Houda Arouri, Mohanmmed Hossain. "Effects of Board and Ownership on Corporate Performance.” Emerald Jan.2014:30-34.

[3] Lipton Martain, Lorsch Jay U.A. “Modest Proposal for Improved Corporate Governance” The Business Lawyer Oct.1992:48-52.

[4] Nuno Fernandes EC. "Board Compensation and Firm Performance: The Role of "Independent Board Members”.”Emerald Feb.2008:30-33.

[5] Olayinka Marte Uadliale. "The Impact of Board Structure on Corporate Financial Performance in Nigeria” DOAJ May.2009:29-35.

[6] Fama and Jensen, "Separation of ownership and control [J]," Journal of law and economics, No. 2, pp. 301-305, 1983.

[7] Paul M .Guest, The Impact of Board Size on Firm Performance:Evidence from the UK”. The European Journal of Finance Dec.2013:50-52.

[8] R. Morck, A. Shleifer and R. W. Vishny. Management ownership and market valuation: An empirical analysis. Journal of Financial Economies, 1988, 20(1-2): 293-315.

[9] Yermack, D.Higher. "Market Valuation of Companies with a Small Board of Directors." Financial Economic Nov.1996:185-211. 